\title{
Mechanizmy funkcjonowania języka w nazwach marketingowych na przykładzie nazewnictwa firmowego
}

\author{
Dorota Biadala \\ Uniwersytet w Heidelbergu \\ dorota.biadala@slav.uni-heidelberg.de
}

\section{Streszczenie}

Przedmiotem niniejszego opracowania jest ustalenie i analiza językowych mechanizmów służących brandingowi, czyli tworzeniu nazw marketingowych we współczesnej chrematonimii na przykładzie polskiego nazewnictwa firmowego. Obiektem niniejszej analizy są różnego rodzaju nazwy firm. Należą do nich zarówno nazwy sklepów, salonów i hurtowni, jak również nazwy zakładów handlowych, rzemieślniczych i usługowych różnorodnych branż: budowlanej, finansowej, gastronomicznej, kosmetycznej, medycznej, motoryzacyjnej, turystycznej itd. Materiał badawczy został zebrany na podstawie Katalogu Firm Serwisu „TuWroclaw.com” dla Wrocławia. Biorąc pod uwagę sposoby tworzenia nazw firmowych w Polsce można zauważyć, że mechanizmy te reprezentują dużą otwartość słowotwórczą i wynikające $\mathrm{z}$ tego bardzo zróżnicowane struktury: 1) jedno- i wielowyrazowe, 2) złożone zarówno $\mathrm{z}$ elementów rodzimych, jak i bardzo modnych współcześnie członów obcego pochodzenia, 3) motywowane bezpośrednio, jak i w sposób pośredni lub 4) całkowicie nieczytelne pod względem słowotwórczym i semantycznym. Analiza nazw firmowych, wpisujących się $\mathrm{w}$ język marketingowy $\mathrm{i}$ związanych $\mathrm{z}$ intensywnym rozwojem cywilizacyjnym, pozwala zauważyć coraz silniej uwidaczniającą się tendencję do ekonomiczności języka.

Stowa kluczowe: onomastyka, chrematonimia, firmonimy

Abstract

Linguistic Mechanisms in Marketing Names on the Example of Company Names

The aim of this paper is to determine and analyse language mechanisms used in branding, i.e. creating marketing names in contemporary chrematonyms on the example of Polish company names. The object of the analysis are various establishment names. These include names of shops, salons and wholesale warehouses, as well as trade, craft and service industries of various sectors: construction, finance, catering, cosmetics, medical, automotive, tourism, etc. The research material was collected on the basis of the Directory of Companies for Wrocław "TuWroclaw.com". Taking into account the ways in which company names are created in 
Poland, it can be seen that these mechanisms represent a great openness to word formations and, as a result, a great openness to very diverse structures: 1) single- and multi-word structures, 2) structures composed of both native and (at present very fashionable) foreign elements, 3 ) structures motivated directly or indirectly, 4) completely illegible structures in terms of word formations and semantics. The analysis of company names which belong to the marketing language and are related to the intensive development of civilization in recent decades allows us to notice an increasingly visible tendency to economise with language.

Keywords: onomastics, chrematonyms, company names

\section{Wstęp}

Nazwa firmy odgrywa niebagatelną rolę w zróżnicowanej przestrzeni komunikacyjnej, jaką tworzą współczesne miasta. Jest nazwą własną sklepów, salonów i hurtowni, jak również zakładów handlowych, rzemieślniczych i usługowych różnorodnych branż: budowlanej, finansowej, kosmetycznej, medycznej, motoryzacyjnej, odzieżowej, sportowej itd. Jest unikatowym, przyciągającym uwagę i wysoce perswazyjnym komunikatem marketingowym, wykorzystującym technikę brandingu, czyli technikę kreowania marki i utrwalania u konsumentów jej pozytywnego odbioru. Wymuszona konkurencyjnością potrzeba rozróżniania i eksponowania firm powoduje nieustanne poszukiwanie nowych sposobów przedstawiania struktur nazewniczych, które swoją innością i oryginalnością mają przykuć uwagę potencjalnych klientów i wzbudzić u nich chęć do kupna towaru lub do skorzystania z oferowanych usług.

\section{Nazewnictwo firmowe}

Badanie nazw firmowych nie jest częstym obiektem zainteresowań onomastów. Skupiają się oni raczej na badaniach antroponimów, czyli nazw własnych osób oraz toponimów, czyli nazw miejscowych. Do nurtu chrematonomastycznego zajmującego się nazewnictwem firmowym należą prace m.in. M. Biolik / J. Dumy (red. 2011), E. Brezy (1998), A. Gałkowskiego ([2008] 2011, 2014), E. Rzetelsko-Feleszko (2006) i A. Siwca (2012).

Nazwa własna firmy odnosi się nie tylko do miejsca czy budynku, ale przede wszystkim odzwierciedla strukturę biznesową. Bliższa analiza nazw firmowych pozwala dostrzec przy tym istotny wpływ aktualnej sytuacji politycznej i uwarunkowań społeczno-gospodarczych na nazewnictwo firmowe. Nazwy firm sprzed 1989 roku są całkowicie odmienne w porównaniu 
z nazwami „wolnorynkowymi”, czyli powstałymi w prokapitalistycznym kontekście politycznym i gospodarczo-społecznym. Po transformacji w 1989 roku znacznie wzrosła też liczba firm i przedsiębiorstw w Polsce, a wraz ze zwiększeniem się liczby lokali firmowych i różnorodnością eksponowania ich nazw zwiększyło się zainteresowanie językoznawców tym typem struktur nazewniczych, zaliczanych do szeroko pojętej chrematonimii. Chrematonim to jest nazwa własna obiektu wytworzonego jako efekt kulturowej działalności człowieka, np. nazwa firmy, produktu, wydarzenia.

Gałkowski, autor artykułu „Motywacja w procesie tworzenia chrematonimii marketingowej” (2014), włącza nazwy firmowe w zakres tzw. chrematonimii marketingowej, którą definiuje jako:

[...] zbiór nazw obiektów przestrzeni gospodarczej (firm, przedsiębiorstw, niektórych rodzajów instytucji, produktów, usług, marek). Chrematonimia marketingowa jest dziś najbardziej dynamicznym polem kreacji nazewniczych, w którym motywacja nazewnicza odgrywa bardzo ważną rolę, decydującą, obok innych okoliczności, o sukcesie ekonomicznym desygnowanych obiektów. Kreacje nazewnicze w chrematonimii marketingowej wchodzą do dyskursu właściwego dla komunikacji w przestrzeni gospodarczej. Narzędzia marketingowe mają tu szerokie zastosowanie.

(Gałkowski 2014: 64-65)

Innymi słowy: motywacja onomastyczna to proces prowadzący do powstania nazwy i pragmatyczno-funkcjonalnego jej ukierunkowania.

Gałkowski przedstawia również klucz motywacyjny chrematonimii marketingowej, który polega na zestawieniu różnych kategorii procesu nazewniczego, a mianowicie: 1) konceptu określającego nazywany obiekt, 2) potrzeby nazewniczej, 3) inspiracji, 4) przeznaczenia nazwy, 5) doboru formy, 6) przekazu informacyjnego zakodowanego w nazwie (Gałkowski 2014: 65).

W monografii Gałkowskiego z 2011 roku można znaleźć liczne przykłady terminów używanych synonymicznie w literaturze przedmiotu, m.in. ergonimy komercyjne, firmonimy, nazewnictwo marketingowe, nazwy handlowe, nazwy na sprzedaż, nazwy obiektów handlowousługowych, nazwy produktów, nazwy przedsiębiorstw (Gałkowski 2011: 37).

Jako najbardziej uniwersalny z punktu widzenia chrematonomastycznego Gałkowski proponuje uznać termin 'firmonim':

Firmonimy jako nazwy własne firm oraz ich produktów/usług (zastrzeżone lub nie) mają postać rozwiniętej marki lub są - choćby potencjalnie - w toku procesu transformacyjnego, który kończy 
się osiągnięciem statusu marki. Są to nazwy rozpoznawalne i funkcjonujące w przestrzeni komunikacyjno-marketingowej, tym samym stanowią składnik jednego z poziomów kulturowoużytkowych języka.

(Gałkowski 2011: 64)

Obecność firmonimów jest nieobowiązkowa, działalność gospodarcza bowiem może być rejestrowana $\mathrm{w}$ obowiązującym systemie prawnym również bez specjalnej nazwy wymyślonej przez przedsiębiorcę (Gałkowski 2011: 67). Chociaż firmonimy stanowią nieobowiązkową część oficjalnej nazwy firmy, to jednak trzeba przyjąć, iż, jeśli się pojawiają, stanowią najbardziej rozpoznawalną część oficjalnej nazwy firmy.

Analizując strukturę nazewniczą, można zaobserwować, że oprócz firmonimów struktura nazewnicza może również zawierać człony deskrypcyjne wskazujące na rodzaj prowadzonej działalności - np. FIRMA HANDLOWO-USŁUGOWA ${ }^{1}$ - oraz imiona i nazwiska właścicieli - np. FIRMA HANDLOWO-USŁUGOWA LARGO LESŁAW KOWALSKI (por. Młynarczyk 2016: 119) ${ }^{2}$. Materiał badawczy został zebrany na podstawie Katalogu Firm Serwisu „TuWroclaw.com” dla Wrocławia z dnia 11-go lutego 2018 roku (4799 firm wrocławskich).

\section{Struktury slowotwórcze firmonimów}

Biorąc pod uwagę sposoby tworzenia firmonimów w nazwach firmowych w Polsce, można zauważyć, że mechanizmy te reprezentują dużą otwartość słowotwórczą i wynikające z tego bardzo zróżnicowane struktury:

1) a) firmonimy jednowyrazowe, np.:

- AEDIUM PAWEŁ DRELICH DAMIAN ZARZYCKI (wycena nieruchomości)

- BŁYSKOTKI USŁUGI PORZĄDKOWE MARTA CISEK (sprzątanie wnętrz i mycie okien)

- CABALA JERZY TRANSPORT I SERWIS SAMOCHODOWY (transport samochodowy, serwis samochodów ciężarowych i dostawczych)

- DOMED EDWARD PAWŁOWSKI (wykańczanie wnętrz, malowanie i tapetowanie)

- FLORIAN SPÓŁDZIELNIA PRACY USŁUG KOMINIARSKICH (usługi kominiarzy)

b) firmonimy wielowyrazowe, np.: 
- CATERING KANAPKOWY PYSZNA BUŁA KRZYSZTOF URBAN (catering, organizacja imprez i konferencji)

- INPROGRESS CLEANING COMPANY KAMIL BARAN (sprzątanie wnętrz i mycie okien)

- OŚRODEK WYPOCZYNKOWO-SZKOLENIOWY MIKSTAT LAS (organizacja imprez i konferencji, hotel)

- VERUM LEX SP. Z O.O. (agencja detektywistyczna, agencja ochrony)

- ZIELONA POMARAŃCZA (usługi ogrodnicze)

2) a) firmonimy złożone $z$ elementów rodzimych, np.:

- CUKIERNIA ŁOMŻANKA (gastronomia)

- DREWPOL FIRMA PRODUKCYJNO-HANDLOWA (produkcja parkietu i paneli podłogowych)

- FILARY ŻYCIA FIRMA SZKOLENIOWO-KONSULTACYJNA ELŻBIETA ŁOZIŃSKA (kursy i szkolenia)

- KLUB 9 BRAMA (gastronomia i rozrywka)

- PORADNIA DIETETYCZNA MAGIA ZDROWIA (zdrowie i medycyna)

b) firmonimy złożone zarówno z elementów rodzimych, jak i z bardzo modnych współcześnie członów obcego pochodzenia, np.:

- DOM $4 U$ SP. Z O.O. (inwestycje budowlane, deweloperzy, budowa i wykończenia pod klucz)

- DRUKARNIA THERISMOS (usługi drukarskie)

- ECO DLA FIRM S.C. (wytwarzanie energii odnawialnej)

- GLASSBUD CONSTRUCTION SP. Z O.O. (budownictwo przemysłowe)

- $M I X B U D$ FIRMA BUDOWLANA FRANCISZKA DROŹDZIEL (budowa i wykończenia pod klucz)

c) firmonimy mające obce pochodzenie, np.:

- AGNOSCO KANCELARIA PRAWNA I. GOGOLEWSKA K. ZAGROBELNY (adwokaci, radcy prawni)

- AIR CONTROL SŁAWOMIR GRUSZKA (tworzywa sztuczne, klimatyzacja, wentylacja)

- BIURO PODRÓŻY TOP-SKI JANUSZ SZOPF (biuro podróży i agencja turystyczna, sprzedaż i rezerwacja biletów)

- $\quad$ QUALITY GUIDE JOANNA KUCHARSKA-CICHOŃ (firma konsultingowa) 
- SILESIABAU SP. Z O.O. (budowa i wykończenia pod klucz)

3) a) motywowane bezpośrednio, np.:

- FIRMA BUDOWLANA TOM-BUD TYNKI MASZYNOWE I INNE USŁUGI TOMASZ GRZEŚNIAK (budowa i wykończenia pod klucz9

- GEOGAL TOMASZ GALICKI (geodezja)

- KANCELARIA ADWOKACKA ADWOKAT ŁUKASZ OPALIŃSKI (adwokaci)

- TOMASZ HAZZAA HATOM (elektroinstalatorstwo)

- WERTE BIURO RACHUNKOWE TERESA KUJAWIŃSKA-WERNER (doradztwo podatkowe, biuro rachunkowe)

b) motywowane w sposób pośredni, np.:

- CTRL ŁUKASZ GĄSIECKI (informatyka)

- FIRMA HANDLOWA LUNA HALINA RUDKIEWICZ (oświetlenie)

- JÓZEF STRĄCZEK FIRMA REMONTOWO-BUDOWLANA STROMO (renowacje i remonty, malowanie i tapetowanie, cegły)

- KREDYT SOS (kredyty i finansowanie)

- SZKOŁA JĘZYKÓW OBCYCH COSMOPOLITAN (szkoły i kursy językowe)

4) niejasne pod względem słowotwórczym i semantycznym, np.:

- ADAXON FIRMA USŁUGOWO-TRANSPORTOWA (transport samochodowy)

- $\quad E L$-VIS FIRMA HANDLOWA (narzędzia)

- FIRMA TRANSPORTOWA RAIKKO KAMIL WÓJTOWICZ (transport samochodowy)

- ISS KESKIN-SAVAS (szkolenia)

- TEATR OGNIA NAM-TARA (kultura i sztuka)

Analiza nazw firmowych Wrocławia pozwala zauważyć coraz silniej uwidaczniającą się tendencję do ekonomiczności języka. Większość współczesnych firmonimów to nazwy jednowyrazowe. Nazwy dwuwyrazowe występują znacznie rzadziej. Dłuższe nazwy i ekspresywne nazwy odprzymiotnikowe tracą coraz bardziej na znaczeniu. 


\section{Techniki nominacyjne}

Wśród technik nominacyjnych daje się zauważyć z jednej strony tendencję do tworzenia struktur nazewniczych, powstałych dzięki środkom tradycyjnym: transonimizacji, wykorzystującej istniejące już $\mathrm{w}$ polszczyźnie słownictwo onomastyczne, a mianowicie antroponimy (imiona i nazwiska) i toponimy (nazwy miejscowe), lub onimizacji (zwanej też proprializacją), czerpiącej materiał językowy z bogatego złoża apelatywnego polszczyzny. Z drugiej zaś strony zaznacza się tendencja do skrótu i ekonomiczności środków językowych, przejawiająca się m.in. w tworzeniu licznych skrótowców przy zastosowaniu derywacji ujemnej wewnątrzsłownej (utworzonej od podstaw apelatywnych lub/i proprialnych) lub uniwerbizacji (czyli zastąpienie określenia dwuwyrazowego jednym wyrazem), do której należą według Szczepańskiej (1994: 17-18) następujące mechanizmy słowotwórcze: derywacja sufiksalna, derywacja dezintegralna, elipsa (substantywizująca i deadjektywizująca), abrewiacja, i kompozycja.

Techniki nominacyjne używane przy tworzeniu firmonimów to:

1) Transonimizacja - antroponimy (nazwy utworzone od imion i/lub nazwisk), $11 \% \mathrm{w}$ badanym korpusie. Przykłady:

- KAWIARNIA MALGOSIA (gastronomia)

- KAWIARNIA OLEŃKA (gastronomia)

2) Transonimizacja - toponimy (nazwy utworzone od nazw miejscowych), 4\% w badanym korpusie. Przykłady:

- MIROSŁAW KULBIDA SANTIAGO (przewozy autokarowe, biura podróży i agencje turystyczne)

- HAWAI BIURO TURYSTYCZNE (usługi turystyczne)

3) Derywacja ujemna wewnątrzsłowna (ucięcie wewnątrzsłowne), 4\% w badanym korpusie. Przykłady:

- JAROSŁAW PAWLAK BUD-TRANS JAR (budowa i transport)

- GEO-EKO FIRMA PROJEKTOWO-WYKONAWCZA (geolodzy i geofizycy, ekologia)

4) Derywacja sufiksalna (nazwy powstałe przez dodanie przyrostka), $<1 \% \mathrm{w}$ badanym korpusie. Przykłady:

- FIRMA HANDLOWA ZLOMEK PIOTR TWOREK (złom i surowce wtórne)

- TRAVELYSTA (usługi turystyczne) 
5) Derywacja dezintegralna (ucięcie całego słowa w wyrażeniu), $<1 \% \mathrm{w}$ badanym korpusie. Przykłady:

- $D O B R A$ (firma konsultingowa)

- APTEKA NOWA (zdrowie i medycyna)

6) Uniwerbizacja eliptyczna (pominięcie słowa określającego firmę), <1\% w badanym korpusie. Przykłady:

- FIRMA IWONA KOWALIK (doradztwo finansowe i kredytowe)

- ANTYKWARIAT (sztuka i kultura, galeria)

7) Abrewiacja (literowce, głoskowce, sylabowce, skrótowce mieszane), 24\% w badanym korpusie. Przykłady:

- $\quad C B S A$ WOJCIECH SKÓRA (agencja detektywistyczna)

- $\quad$ eMTe (sprzątanie i mycie okien)

- eWINit (oprogramowanie komputerowe)

- Mocar CZESŁAW WIŚNIEWSKI (regeneracja części samochodowych, mechanika samochodowa)

- PARYS PAWEŁ RYPL (plandeki)

8) Kompozycja (tworem są złożeniowce, czyli hybrydy z dodatkiem obcych formantów), 56\% w badanym korpusie. Przykłady:

- COOL-TECH ŁUKASZ GŁOGOWSKI (budowa i wykończenia pod klucz)

- PROEKOEKSPERT MARTA BOROWIEC (ochrona środowiska)

- GEOBAK PRACOWNIA GEODEZYJNO-KARTOGRAFICZNA INŻ. MICHAŁ BĄK (geodezja, mapy i plany)

- MIROBUD PHU MIROSŁAW BŁĄKAŁA (wykańczanie wnętrz, budowa i wykończenia pod klucz)

- BYSTRAVISION FIRMA KONSULTINGOWA (firma konsultingowa)

\section{Wnioski}

Analiza jakościowa materiału wykazała, że mechanizmy tworzenia nazewnictwa firmowego sprowadzają się przede wszystkim a) do technik kompozycyjnych (56\% w badanym korpusie), których tworem są tzw. złożeniowce, czyli hybrydy z dodatkiem obcych formantów, struktur zawierających człon utożsamiający nazwę z daną branżą i typem działalności firmy czy wreszcie modne człony o charakterze internacjonalizmów oraz b) do technik abrewiacyjnych 
(24\% w badanym korpusie), głównie utworzonych od podstaw wielowyrazowych, dzięki czemu nazewnictwo firmowe przybiera najczęściej formy różnego typu skrótów i skrótowców (24\% w badanym korpusie). Natomiast inne mechanizmy słowotwórcze, takie jak transonimizacja antroponimiczna (11\% w badanym korpusie), transonimizacja toponimiczna (4\%), derywacja ujemna wewnątrzsłowna (4\%), derywacja sufiksalna $(<1 \%)$, derywacja dezintegralna $(<1 \%)$, czy uniwerbizacja eliptyczna $(<1 \%)$ mają znikomy udział w tworzeniu nazw firmowych.

Na zakończenie warto dodać, że można by jeszcze się zastanowić, czy wskazane powyżej techniki nominacyjne umożliwiają w zadawalającym stopniu przeprowadzenie klasyfikacji wszystkich firmonimów. Jak już wspomniałam, liczne nazwy firmowe to twory hybrydalne, w których przemieszane są różne techniki słowotwórcze i które bardzo trudno precyzyjnie sklasyfikować, jak np. DAW_JOL, DOM4U, P2 ARCHITEKCI, WIERCONESTUDNIE.PL. Według mnie należałoby przeprowadzić dodatkowe badania, prowadzące do zdefiniowania innych możliwych typów mechanizmów tworzenia nazewnictwa firmowego, w szczególności różnych typów hybrydowych, które wraz z istniejącymi już typami umożliwiłyby precyzyjny opis struktury wszystkich nazw firmowych.

\section{Przypisy}

${ }^{1}$ Ze względu na różne sposoby zapisu firmonimów oraz różne ich miejsce w strukturze nazewniczej, wprowadzam jednolity zapis chrematonimów kapitalikami.

${ }^{2}$ Cytując całą strukturę chrematonimu firmonim wyróżniam kursywą.

\section{Bibliografia}

Biolik, Maria, Jerzy Duma (red.) (2011) Chrematonimia jako fenomen współczesności.

Olsztyn: Wydawnictwo Uniwersytetu Warmińsko-Mazurskiego.

Breza, Edward (1998) „Nazwy obiektów i instytucji związanych z nowoczesną cywilizacją (chrematonimy)”. [W:] Ewa Rzetelska-Feleszko (red.) Polskie nazwy własne.

Encyklopedia. Warszawa-Kraków: Instytut Języka Polskiego PAN; 343-361.

Gałkowski, Artur ([2008] 2011) Chrematonimy w funkcji kulturowo-użytkowej. Onomastyczne studium porównawcze na materiale polskim, włoskim, francuskim. Wyd. 2.; Łódź:

Wydawnictwo Uniwersytetu Łódzkiego.

Gałkowski, Artur (2014) „Motywacja w procesie tworzenia chrematonimii marketingowej”. Poznańskie Spotkania Językoznawcze XXVII; 63-72. 
Młynarczyk, Ewa (2016) „Modne nazwy firmowe (na przykładzie nazw salonów kosmetycznych)”. Poznańskie Spotkania Językoznawcze XXXII; 117-125.

Rzetelsko-Feleszko, Ewa (2006) W świecie nazw własnych. Warszawa-Kraków: Towarzystwo Naukowe Warszawskie.

Siwiec, Adam (2012) Nazwy własne obiektów handlowo-ustugowych w przestrzeni miasta. Lublin: Wydawnictwo Uniwersytetu Marii Curie-Skłodowskiej.

Szczepańska, Elżbieta (1994) Uniwerbizacja w języku czeskim i polskim. Kraków: Universitas; $17-18$. 